\title{
A critical humidity threshold for monsoon transitions
}

\author{
J. Schewe ${ }^{1,2}$, A. Levermann ${ }^{1,2}$, and H. Cheng ${ }^{3,4}$ \\ ${ }^{1}$ Earth System Analysis, Potsdam Institute for Climate Impact Research, 14473 Potsdam, Germany \\ ${ }^{2}$ Institute of Physics, University of Potsdam, 14476 Potsdam, Germany \\ ${ }^{3}$ Institute of Global Environmental Change, Xi' an Jiaotong University, Xi' an, 710049, China \\ ${ }^{4}$ Department of Geology and Geophysics, University of Minnesota, Minneapolis, 55455, USA
}

Correspondence to: J. Schewe (jacob.schewe@ pik-potsdam.de)

Received: 4 May 2011 - Published in Clim. Past Discuss.: 30 May 2011

Revised: 20 February 2012 - Accepted: 28 February 2012 - Published: 15 March 2012

\begin{abstract}
Monsoon systems around the world are governed by the so-called moisture-advection feedback. Here we show that, in a minimal conceptual model, this feedback implies a critical threshold with respect to the atmospheric specific humidity $q_{\mathrm{o}}$ over the ocean adjacent to the monsoon region. If $q_{\mathrm{o}}$ falls short of this critical value $q_{\mathrm{o}}^{\mathrm{c}}$, monsoon rainfall over land cannot be sustained. Such a case could occur if evaporation from the ocean was reduced, e.g. due to low sea surface temperatures. Within the restrictions of the conceptual model, we estimate $q_{\mathrm{o}}^{\mathrm{c}}$ from present-day reanalysis data for four major monsoon systems, and demonstrate how this concept can help understand abrupt variations in monsoon strength on orbital timescales as found in proxy records.
\end{abstract}

\section{Introduction}

Monsoon rainfall is the major prerequisite of agricultural productivity in many tropical and subtropical regions of the world, and its variability has been affecting the livelihoods of a large share of the world's population from ancient civilizations until today (e.g. Parthasarathy et al., 1988; Kumar et al., 2004; Auffhammer et al., 2006; Zhang et al., 2008; Rashid et al., 2011). Proxy records show evidence of abrupt and strong monsoon shifts during the last two glacial cycles (Burns et al., 2003; P. Wang et al., 2005; Wang et al., 2008) and the Holocene (Gupta et al., 2003; Hong et al., 2003; Y. Wang et al., 2005; Rashid et al., 2011) in India, the Bay of Bengal, and East Asia. In many instances in the past, periods of strong monsoon rainfall thus appear to have alternated with periods of prolonged drought, with comparatively rapid transitions between the two.

Both spatial patterns and temporal evolution of continental monsoon rainfall are influenced by a number of physical processes (Hahn and Shukla, 1976; Webster et al., 1998; Kr- ishnamurthy and Goswami, 2000; Clark et al., 2000; Srinivasan, 2001; Kucharski et al., 2006; Goswami et al., 2006; Goswami and Xavier, 2005; Dash et al., 2005; Ramanathan et al., 2005; Wang, 2005; Yang et al., 2007) as well as characteristics of vegetation (Meehl, 1994; Claussen, 1997; Robock et al., 2003) and topography (Liu and Yin, 2002). Though these details are crucial for the specific behavior of different monsoon systems, and their significance will vary from region to region, there exist defining processes that are fundamental to any monsoon dynamics (e.g. Webster, 1987a,b). These are the advection of heat and moisture during the monsoon season and the associated rainfall and release of latent heat. While differential heating of land and ocean in spring is important for the initiation of the monsoon season, land surface temperatures drop substantially after the onset of heavy precipitation, diminishing the surface temperature gradient. The monsoon circulation over the continent is thereafter predominantly sustained by the release of latent heat and subsequent warming of the atmospheric column over land (Webster et al., 1998). Using a complex conceptual model, Zickfeld et al. (2005) found that a monsoon circulation that is sustained by the moisture-advection feedback can undergo abrupt changes in response to changes in the land surface albedo. Knopf et al. (2006) however showed that the threshold albedo in this model is very far away from modern conditions and is highly uncertain due to the dependence on various model parameters.

Here we apply a minimal conceptual model that comprises the heat and moisture budgets of an idealized monsoon circulation. It reflects the dominant role of the self-amplifying moisture-advection feedback during the monsoon season, which is supported by observations (Levermann et al., 2009). We show that the model yields a threshold behaviour with respect to the atmospheric humidity over the ocean adjacent to the monsoon region. Below the threshold, the advection and release of latent heat are not sufficient to sustain monsoon 


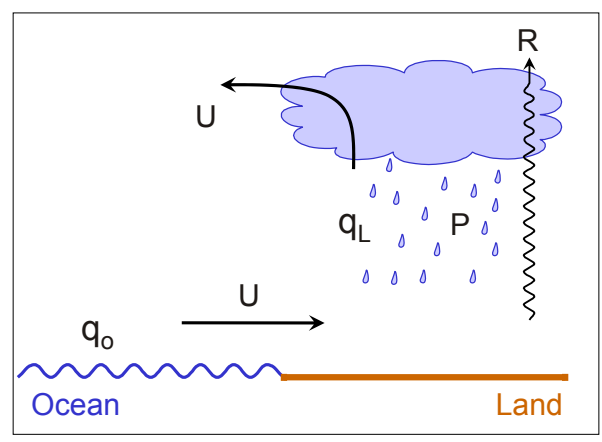

Fig. 1. Geometry of the conceptual model, illustrating wind $U$, precipitation $P$, net radiative flux $R$, and atmospheric specific humidity over land $\left(q_{\mathrm{L}}\right)$ and ocean $\left(q_{\mathrm{o}}\right)$.

rainfall over land. It is important to note that globally, rainfall associated with the intertropical convergence zone will naturally be sustained even without continental monsoon rainfall. Furthermore, the seasonal reversal of cross-equatorial winds, driven by the seasonal change in hemispheric insolation, is not affected by our analysis. The question addressed here is which conditions are necessary in order to sustain a rainy season over land beyond the zonal-mean dynamics of the intertropical convergence zone. The basic dynamics captured in our model thus form a necessary condition for continental monsoon rainfall to exist.

This paper is organized as follows: we describe the conceptual model in Sect. 2 and analyse its implications in Sect. 3. In Sect. 4, the critical threshold is estimated for four major monsoon regions. In Sect. 5, we apply the model to abrupt monsoon changes on orbital timescales. Section 6 concludes.

\section{Conceptual model}

We use the minimal conceptual model presented by Levermann et al. (2009) (see illustration in Fig. 1). It is based on the observation that, during the rainy season, the regionalscale moist static energy balance of the tropospheric column over land is dominated by latent heating due to precipitation, which is balanced by advective (including synoptic and small-scale heat transport processes) as well as radiative cooling. According to NCEP/NCAR reanalysis data (19482007; Kistler et al., 2001), this holds for all major monsoon regions (Levermann et al., 2009). The moist static energy balance of the tropospheric column can thus be approximated by

$\mathcal{L} \cdot P-\epsilon C_{p} U \cdot \Delta T+R=0$,

where $\Delta T$ is the tropospheric temperature difference between land and ocean, and $P$ is the mean precipitation over land (in $\mathrm{kg} \mathrm{m}^{-2} \mathrm{~s}^{-1}$ ). Latent heat of condensation is $\mathcal{L}=2.6 \times 10^{6} \mathrm{~J} \mathrm{~kg}^{-1}$ and volumetric heat capacity of air $C_{p}=1295 \mathrm{~J} \mathrm{~m}^{-3} \mathrm{~K}^{-1}$. The ratio $\epsilon=H / L$ between vertical
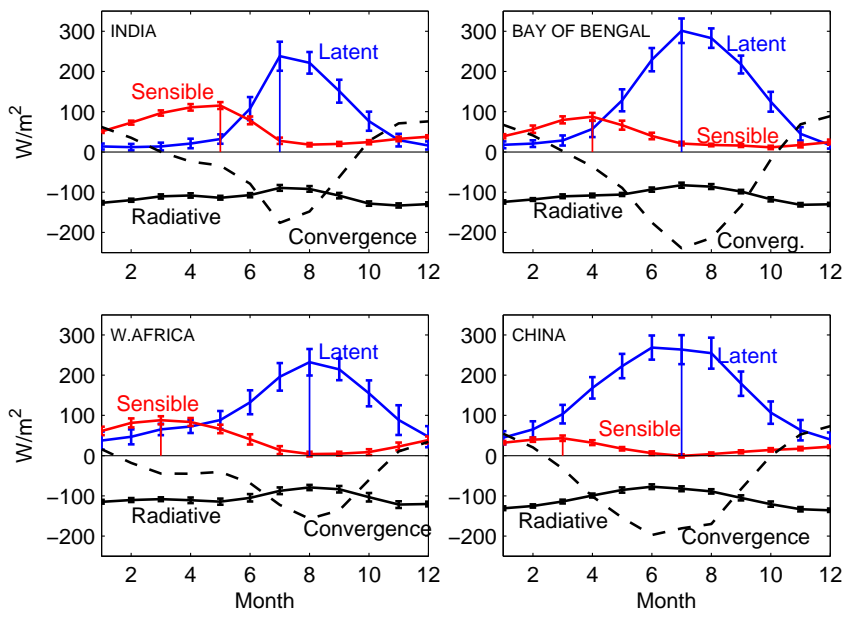

Fig. 2. Seasonal heat flux contributions to the atmospheric column over four major continental monsoon regions in NCEP/NCAR reanalysis data (Kistler et al., 2001). Radiative heating of the land surface in spring enhances sensible heat flux from the ground ("Sensible"). During the rainy season, latent heat release dominates the heat budget ("Latent"). Radiative heat flux comprises all radiative fluxes in and out of the atmospheric column ("Radiative"). The excess heat is transported out of the continental monsoon region through large-scale advective and synoptic processes ("Convergence"). Error bars give the standard deviation from the reanalysis period (1948-2007). See Table 1 for the geographical definitions of the monsoon regions. The red and blue vertical lines emphasize the months of maximum sensible heat flux and latent heat flux, respectively.

extent $H$ of the lower troposphere and the horizontal scale $L$ of the region of precipitation enters due to the balance of the horizontal advective heat transport and the vertical fluxes of net radiative forcing $R$ and precipitation $P$. Note that this is a model of the monsoon season only, and includes no annual cycle. The above balance therefore neglects the contribution from sensible heating, which is important at the onset stage but relatively weak once heavy rainfall has started to cool the land surface (Fig. 2). Consequently, this model does not capture any interseasonal or interannual dynamics. In particular, we take the development of a strong land-ocean surface temperature contrast during springtime as a given, and focus on the conditions needed to sustain the resulting atmospheric temperature contrast $\Delta T$ throughout the monsoon season, even after sensible heating from the surface has become small.

$U$ is generally the rate of air mass exchange between the land and ocean regions given by the monsoon overturning circulation. It can be represented by the lower-level wind strength. Equations are only valid for landward lower-level winds, $U \geq 0$. That means that situations in which no solution of the model with positive $U$ can be found will be considered as a parameter and force combinations for which no monsoon rainfall can be sustained. 

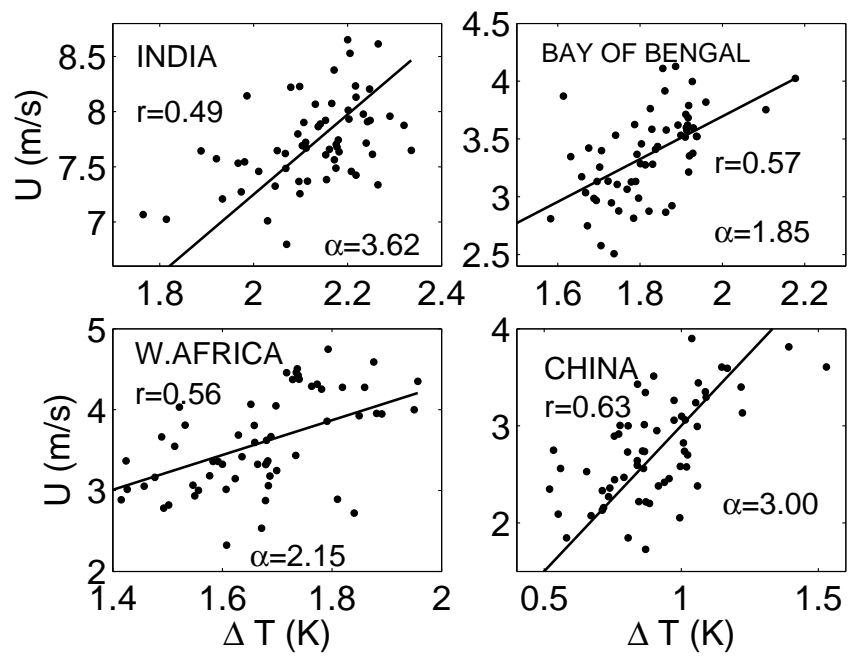

Fig. 3. Wind $U$ versus temperature difference between land and ocean region, $\Delta T$, from NCEP/NCAR reanalysis data, for the major monsoon regions of India, the Bay of Bengal, West Africa, and China (East Asia; see Table 1). The correlation coefficient $r$ is indicated, as well as the slope $\alpha$ of a linear fit through the origin (black line).

Assuming dominance of ageostrophic flow in low latitudes, $U$ is taken to be proportional to the temperature difference between land and ocean (Petoukhov, 1982; Webster, 1987a; Brovkin et al., 1998):

$U=\alpha \cdot \Delta T$.

Reanalysis data confirm that this is a valid first-order approximation (Fig. 3). Neglecting the effect of evaporation over land (which will be discussed below) and associated soil moisture processes, precipitation has to be balanced by the net landward flow of moisture

$\rho \epsilon U \cdot\left(q_{\mathrm{o}}-q_{\mathrm{L}}\right)-P=0$,

where $q_{\mathrm{o}}$ is the specific humidity over ocean within the lower, landward branch of the monsoon circulation, and $q_{\mathrm{L}}$ is the specific humidity over land that is advected out of the monsoon region. Consistent with reanalysis data (Fig. 4) and theoretical considerations (Petoukhov, 1982; Petoukhov et al., 2000), continental rainfall is assumed to be proportional to the mean specific humidity within the tropospheric column:

$P=\beta q_{\mathrm{L}}$.

Herein, $q_{\mathrm{L}}$ can be identified with $q_{\mathrm{L}}$ in Eq. (3), because it only needs to represent a robust measure for precipitation, not the exact humidity at the level of condensation. Reanalysis data confirm that the correlation between $P$ and $q_{\mathrm{L}}$ is rather insensitive to the exact choice of height level, as can be expected from a strong mixing due to intense convection. Note that the proportionality constants $\alpha$ and $\beta$ have explicit physical interpretations. $\alpha$ is essentially a function of the
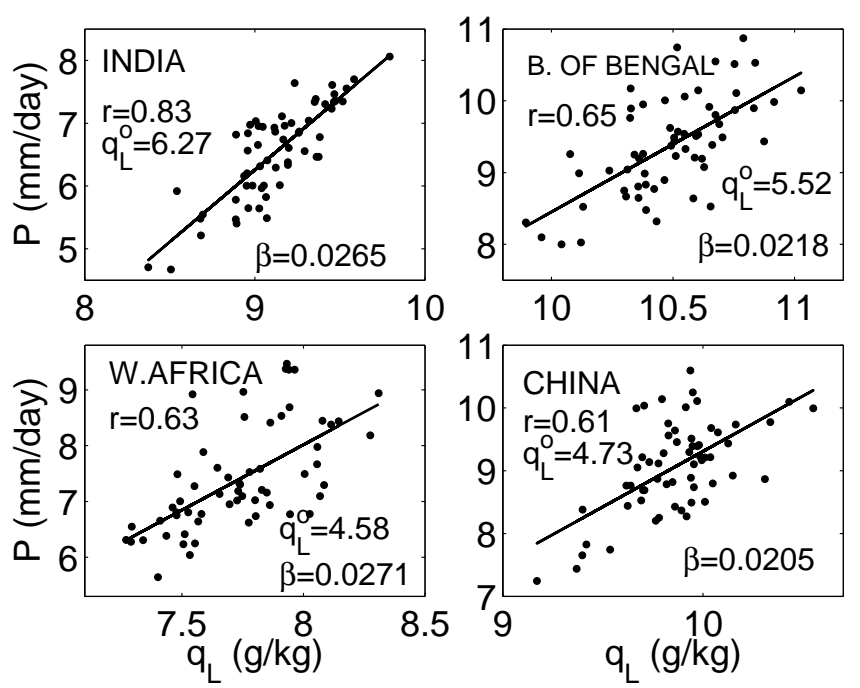

Fig. 4. Precipitation $P$ versus specific humidity over land, $q_{\mathrm{L}}$, from NCEP/NCAR reanalysis data. The black line shows the result of a linear regression, the correlation coefficient $\mathrm{r}$ is indicated, as well as the slope $\beta$ (in $\mathrm{kg} \mathrm{m}^{-2} \mathrm{~s}^{-1}$ ) and the offset in terrestrial humidity, $q_{\mathrm{L}}^{\mathrm{o}}$ (in $\mathrm{g} \mathrm{kg}^{-1}$ ).

near-surface cross-isobar angle and thereby a function of surface roughness and static stability of the planetary boundary layer (PBL); $\beta$ is governed by the characteristic turnover (recycling) time of liquid water in the atmosphere and thereby determined by static stability and vertical velocity in the PBL (Petoukhov et al., 2000). While Eqs. (1) to (4) are the basic relations necessary to capture the moisture-advection feedback, Eq. (4) can be made more realistic by considering an offset in $q_{\mathrm{L}}$, which will be discussed further below.

\section{Critical $q_{0}$ threshold for monsoon existence}

From Eqs. (1), (3) and (4) it follows that

$\mathcal{L} \beta q_{\mathrm{o}}=\left(1+\frac{\beta}{\epsilon \rho U}\right) \epsilon C_{p} U \cdot \Delta T-\left(1+\frac{\beta}{\epsilon \rho U}\right) \cdot R$.

This equation represents the heat budget of the conceptual monsoon circulation in terms of latent heat. The two terms on the r.h.s. represent the loss of heat from the land region by advection of warm air and by radiation, respectively (note that $R<0$ ). Their sum must be balanced by latent heat as provided by the inflow of humid air from the ocean, namely $\mathcal{L} \beta q_{\mathrm{o}}$. The term $(1+\beta / \epsilon \rho U)$ incorporates the fact that the latent heat has to be transported from ocean to land by means of advection; the lower the advective velocity $U$, the higher the specific humidity $q_{\mathrm{o}}$ that is necessary to provide the required amount of latent heat to the atmospheric column over land. 


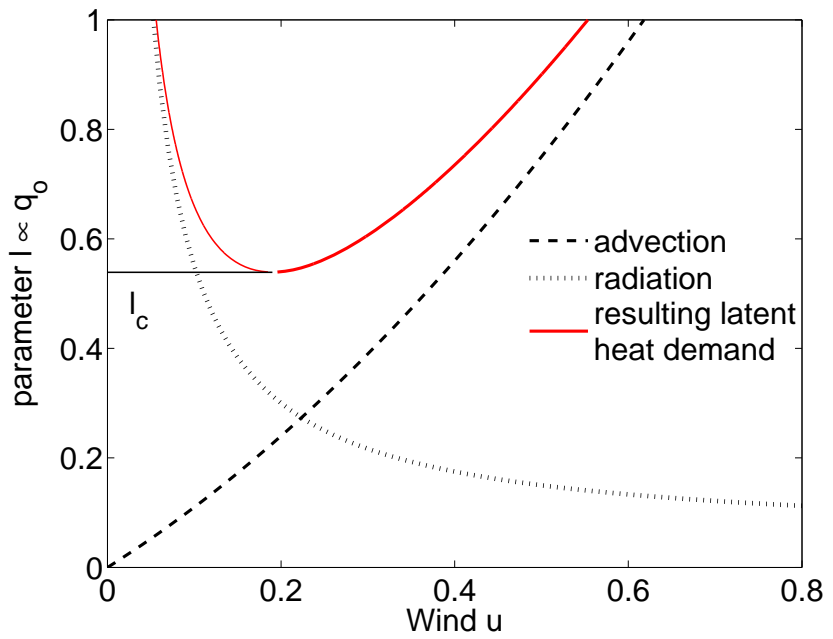

Fig. 5. Solution structure of the conceptual model as a function of the non-dimensional parameter $l$, which is proportional to specific humidity over the ocean, $q_{\mathrm{o}}$. For illustrative purposes, $l$ is plotted on the y-axis. The latent heat demand (red line; bold part indicates the stable branch) results from heat loss due to net radiative flux (dotted) and advection of warm air out of the land region (dashed).

Using Eq. (2) and the relations $u \equiv U \epsilon \rho / \beta$, $r \equiv R \cdot \epsilon \alpha \rho /\left(C_{p} \beta^{2}\right), \quad$ and $\quad l \equiv\left(\epsilon \alpha \rho^{2} \mathcal{L} q_{\mathrm{o}}\right) /\left(C_{p} \beta\right), \quad$ the non-dimensional form of Eq. (5) is obtained:

$l=\left(1+u^{-1}\right) \cdot u^{2}-\left(1+u^{-1}\right) \cdot r$

where $l$ is proportional to $q_{\mathrm{o}}$. This is the governing equation of the conceptual model. Its solution is determined entirely by the only free parameter $r$. The physical part $(l \geq 0$, $u \geq 0$ ) of the solution of Eq. (6) is shown in Fig. 5 for the case $r=-0.05$, where the thick red line denotes a stable solution and the thin red line an unstable one. The advective (dashed line) and radiative (dotted line) terms are also plotted separately to show how the solution is obtained as the sum of these two contributions (to illustrate this, the figure is organized with the control variable $l$ on the y-axis). In the case $r \equiv 0$, only the advective part of the solution remains (i.e. the red line would collapse onto the dashed line). The y-axis in Fig. 5 can be interpreted as the demand in latent heating that results from the loss of heat from the land region due to radiation and advection.

It turns out that no physical solution exists below a critical threshold $l_{\mathrm{c}}$ (horizontal line in Fig. 5), which corresponds to a critical value of specific humidity over the ocean, $q_{\mathrm{o}}^{\mathrm{c}}$. When $q_{\mathrm{o}}$ falls short of this value, the supply of moisture is not sufficient to maintain the monsoon circulation driven by the moisture-advection feedback. No conventional monsoon circulation can thus develop in a climate where $q_{\mathrm{o}}<q_{\mathrm{o}}^{\mathrm{c}}$.

Equation (6) can also be expressed in terms of nondimensional precipitation $p \equiv P /\left(q_{\mathrm{o}} \beta\right)$, which is directly related to the wind through

$p=u /(1+u)$.

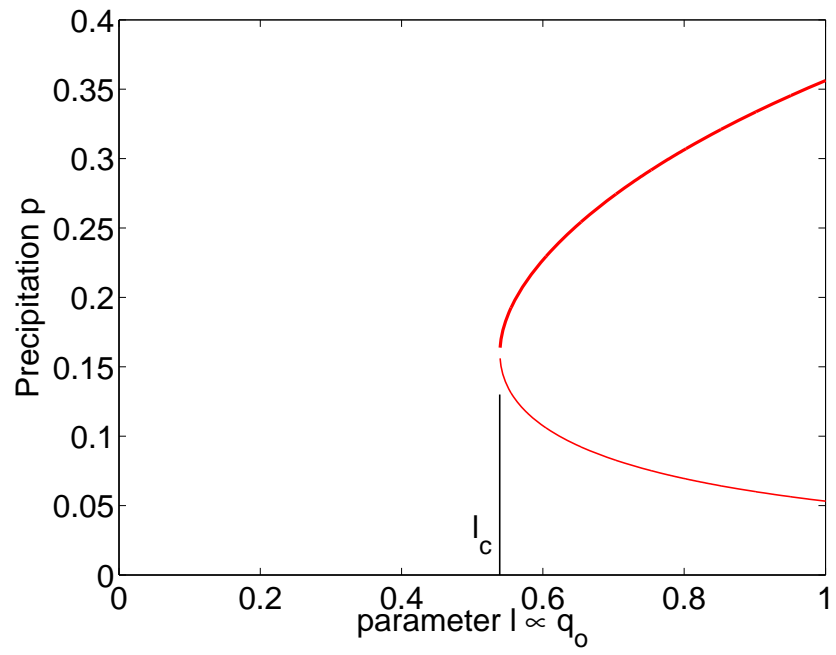

Fig. 6. As Fig. 5 (red line), but in terms of non-dimensional precipitation $p$, and organized with the control parameter $l$ on the $\mathrm{x}$-axis.

The solution in terms of $p$ has a similar shape as in terms of $u$ (Fig. 6), while dimensional precipitation $P$ scales approximately linearly, with $l$ as long as $l$ is sufficiently above the threshold $l_{\mathrm{c}}$ (Fig. 7). While we do not expect to find this quasi-linear relation perfectly reflected in observations, NCEP/NCAR reanalysis data show that seasonal mean precipitation and specific humidity over ocean are correlated to some extent (Fig. 8).

\section{Estimation of the critical threshold $q_{0}^{c}$}

The critical value of the control variable $l$, or equivalently $q_{\mathrm{o}}$, together with the associated value of a given dependent variable (e.g. wind, precipitation, or temperature gradient), defines the critical point, e.g., $\left[l_{\mathrm{c}}, u_{\mathrm{c}}\right]$ (or $\left.\left[q_{\mathrm{o}}^{\mathrm{c}}, u_{\mathrm{c}}\right]\right)$. The critical point will vary for different monsoon systems. It is determined by the non-dimensional radiation $r$ via

$-u_{\mathrm{c}}^{2}\left(2 u_{\mathrm{c}}+1\right)=r$.

The critical $l$ can then be computed from

$l_{\mathrm{c}}=2 u_{\mathrm{c}}\left(u_{\mathrm{c}}+1\right)^{2}$,

and the critical humidity threshold $q_{\mathrm{o}}^{c}$ via the definition of $l$. Within the limitations of this minimal conceptual model, we estimate $q_{\mathrm{o}}^{\mathrm{c}}$ for four different monsoon regions. We use seasonal mean precipitation $P$, radiation $R$, land-ocean temperature difference $\Delta T$, and specific humidity over ocean $q_{\mathrm{o}}$ from the NCEP/NCAR reanalysis to compute time series for $\alpha(t)=(\mathcal{L} P+R) /\left(\epsilon C_{p} \Delta T^{2}\right)$, $\beta(t)=((\mathcal{L} P+R) \cdot \rho P) /\left((\mathcal{L} P+R) q_{\mathrm{o}} \rho-C_{p} \Delta T P\right), \quad$ and $r(t)=R \cdot \epsilon \alpha(t) /\left(C_{p} \beta(t)^{2}\right)$, assuming applicability of the model and stationary statistics within the observational period (1948-2007). Because the observational period is 
Table 1. Regional definitions used for data analysis. Monthly-mean NCEP/NCAR reanalysis data has been averaged over the indicated regions and seasons; land and ocean indicate that only terrestrial or oceanic grid points have been considered, respectively; and $\Delta T=T_{\mathrm{L}}-T_{\mathrm{O}}$. The bottom row lists the values for the dimensionless parameter $\epsilon$ that have been used in the estimation of the critical threshold (see Sect. 4).

\begin{tabular}{lllll}
\hline Quantity & INDIA & B. O. BENGAL & W. AFRICA & CHINA (EASM) \\
\hline$P, R, q_{\mathrm{L}}$ (land) & $70-90^{\circ} \mathrm{E}$ & $80-100^{\circ} \mathrm{E}$ & $15^{\circ} \mathrm{W}-10^{\circ} \mathrm{E}$ & $100-120^{\circ} \mathrm{E}$ \\
& $5-30^{\circ} \mathrm{N}$ & $15-30^{\circ} \mathrm{N}$ & $2-14^{\circ} \mathrm{N}$ & $20-32^{\circ} \mathrm{N}$ \\
$q_{\mathrm{o}}$ (ocean) & $65-78^{\circ} \mathrm{E}$ & $80-100^{\circ} \mathrm{E}$ & $20-15^{\circ} \mathrm{W}, 2-14^{\circ} \mathrm{N} ;$ & $105-115^{\circ} \mathrm{E}$ \\
& $5-30^{\circ} \mathrm{N}$ & $10-20^{\circ} \mathrm{N}$ & $5^{\circ} \mathrm{W}-10^{\circ} \mathrm{E}, 2^{\circ} \mathrm{S}-7^{\circ} \mathrm{N}$ & $15-25^{\circ} \mathrm{N}$ \\
$T_{\mathrm{L}}$ (land) & $70-90^{\circ} \mathrm{E}$ & $80-100^{\circ} \mathrm{E}$ & $10^{\circ} \mathrm{W}-10^{\circ} \mathrm{E}$ & $100-120^{\circ} \mathrm{E}$ \\
& $5-30^{\circ} \mathrm{N}$ & $15-30^{\circ} \mathrm{N}$ & $0-20^{\circ} \mathrm{N}$ & $20-32^{\circ} \mathrm{N}$ \\
$T_{\mathrm{O}}$ (ocean) & $65-78^{\circ} \mathrm{E}$ & $80-100^{\circ} \mathrm{E}$ & $10^{\circ} \mathrm{W}-10^{\circ} \mathrm{E}$ & $105-115^{\circ} \mathrm{E}$ \\
& $5-30^{\circ} \mathrm{N}$ & $10-20^{\circ} \mathrm{N}$ & $10^{\circ} \mathrm{S}-5^{\circ} \mathrm{N}$ & $15-25^{\circ} \mathrm{N}$ \\
$U$ (westerly) & $65-78^{\circ} \mathrm{E}$ & $80-100^{\circ} \mathrm{E}$ & $20-10^{\circ} \mathrm{W}$ & \\
& $5-30^{\circ} \mathrm{N}$ & $15-30^{\circ} \mathrm{N}$ & $5-14^{\circ} \mathrm{N}$ & $100-120^{\circ} \mathrm{E}$ \\
$U$ (southerly) & & & $5^{\circ} \mathrm{W}-10^{\circ} \mathrm{E}$ & $20-32^{\circ} \mathrm{N}$ \\
\hline \multirow{2}{*}{ Monsoon season } & Jun-Aug & Jun-Aug & Jul-Sep & Jun-Aug \\
\hline$\epsilon$ & $4.5 \times 10^{-3}$ & $2.3 \times 10^{-2}$ & $1.7 \times 10^{-2}$ & $6.7 \times 10^{-2}$ \\
\hline
\end{tabular}

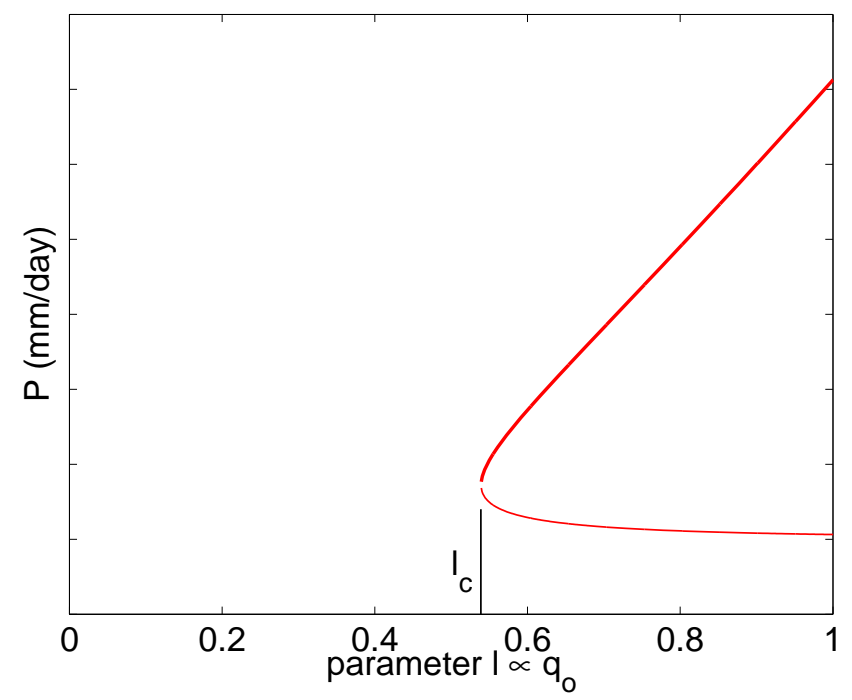

Fig. 7. As Fig. 6, but in terms of dimensional precipitation $P$. The shape of the solution is different than in terms of $p$, because the relation between $p$ and $P$ depends on $l$. Units on the y-axis are arbitrary.

subject to significant anthropogenic global warming, we remove a linear trend from all reanalysis data to get a closer approximation of a stationary climate. From $\alpha(t), \beta(t)$ and $r(t), q_{\mathrm{o}}^{\mathrm{c}}$ can then be obtained for each year via Eqs. (8), (9) and the definition of $l$. Note that $q_{\mathrm{o}}^{\mathrm{c}}$ is independent of $\epsilon$, the only quantity that is not constrained by data. The resulting $q_{\mathrm{o}}^{\mathrm{c}}$ distribution (Fig. 9, blue) is much lower than the observed distribution of $q_{\mathrm{o}}$ (black) in the Bay of Bengal, West Africa and China, while in India the distributions are closer. The
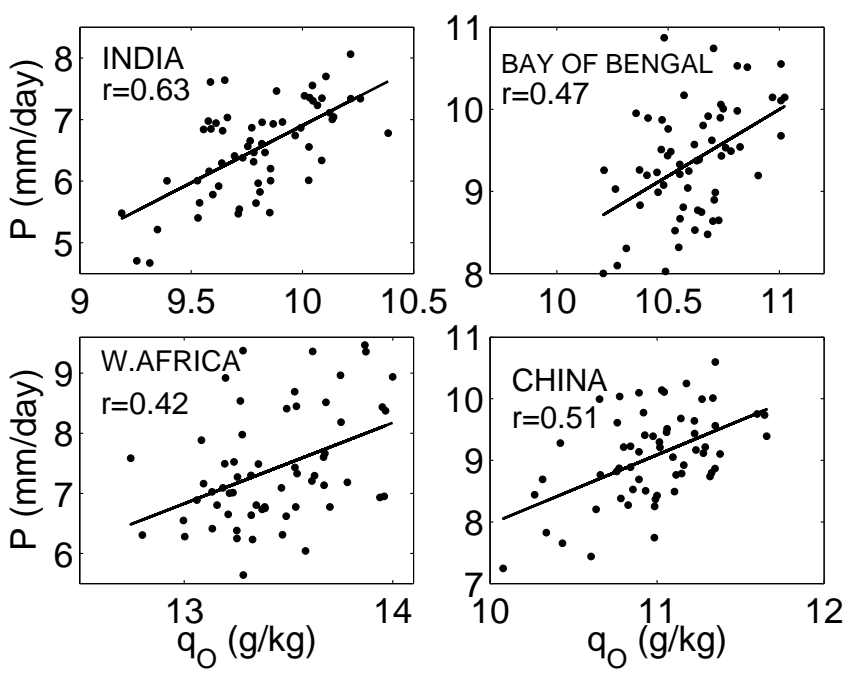

Fig. 8. Correlation between precipitation and specific humidity over the ocean from NCEP/NCAR reanalysis data. Black lines show the result of a linear regression; the correlation coefficients are indicated.

blue pin marks the $q_{\mathrm{o}}^{\mathrm{c}}$ estimate that is obtained from the time-mean values $\overline{\alpha(t)}, \overline{\beta(t)}$ and $\overline{R(t)}$.

The spread in the distribution of $q_{\mathrm{o}}^{\mathrm{c}}$ is due to substantial variability in $\alpha(t), \beta(t)$ and $r(t)$ throughout the reanalysis period. The interannual variability in the dimensional net radiation $R$ is about $15-20 \%$ during the reanalysis period, depending on the region. On longer timescales, $R$ can be expected to be rather stable because of the negative longwave radiation feedback according to the Stefan-Boltzmann 

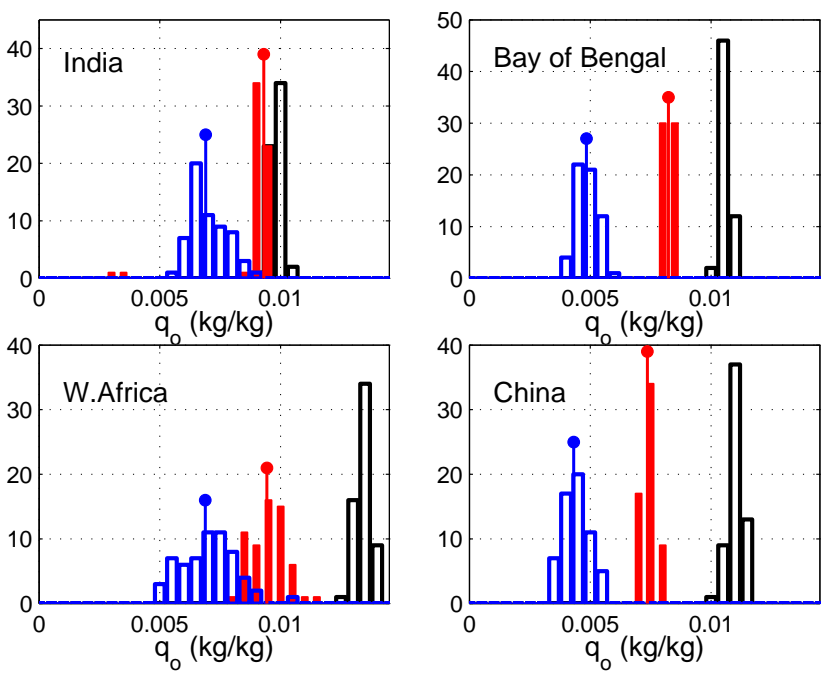

Fig. 9. Estimate of critical specific humidity value over the ocean, $q_{\mathrm{o}}^{\mathrm{c}}$, from NCEP/NCAR reanalysis data for the basic minimal model (blue) and including the effect of a minimum terrestrial humidity $q_{\mathrm{L}}^{\mathrm{O}}$ required for the onset of precipitation (red). The black histogram shows the observed distribution of $q_{\mathrm{o}}$. Pins mark the estimates obtained from time-mean parameter values.

law. However, the factors $\alpha$ and $\beta$ may also vary over time. Moreover, in reality the basic relations of Eqs. (2) and (4) are blurred by higher-order physical processes that are not represented in our idealized model, limiting our ability to determine $\alpha$ and $\beta$ (cf. Figs. 3 and 4). Depending on the relative importance of actual variability and observational uncertainty, the distribution of $q_{\mathrm{o}}^{\mathrm{c}}$ can be interpreted either (i) as a noisy estimate of a stationary critical threshold, or (ii) as a probability distribution of an interannually varying threshold.

In order to obtain more realistic estimates of $q_{\mathrm{o}}^{\mathrm{c}}$, we extend Eq. (4) by an offset $q_{\mathrm{L}}^{\mathrm{o}}$ that terrestrial humidity $q_{\mathrm{L}}$ needs to exceed before precipitation is initiated (as suggested by the correlation in Fig. 4):

$P=\beta\left(q_{\mathrm{L}}-q_{\mathrm{L}}^{\mathrm{o}}\right)$

After replacing $q_{\mathrm{o}}$ by $\left(q_{\mathrm{o}}-q_{\mathrm{L}}^{\mathrm{o}}\right)$ in the definitions of $l$ and $p$, the non-dimensional Eqs. (6)-(9) remain unchanged.

As above, we estimate $q_{\mathrm{o}}^{\mathrm{c}}$ for this refined version of the model, obtaining the parameter $q_{\mathrm{L}}^{\mathrm{o}}$ from linear regression of the corresponding reanalysis data (Fig. 4). Note that, due to Eq. (10), $q_{\mathrm{o}}^{\mathrm{c}}$ now also depends on $\epsilon . \epsilon$ is generally of the order of a few kilometers $(H)$ over hundreds of kilometers $(L)$, but only loosely constrained by the approximate extents of the monsoon regions. Within reasonable bounds, we choose $\epsilon$ such that $\overline{\alpha(t)}$ matches the $\alpha$ that we observe as the slope of the linear regression between $U$ and $\Delta T$ shown in Fig. 3 (see Table 1). The results for $q_{\mathrm{o}}^{\mathrm{c}}$ are shown in Fig. 9 (red), where again the pin marks the estimate from mean quantities. The consideration of the offset $q_{\mathrm{L}}^{\mathrm{o}}$ generally yields a distribution of $q_{\mathrm{o}}^{\mathrm{c}}$, which is narrower and closer to, while still

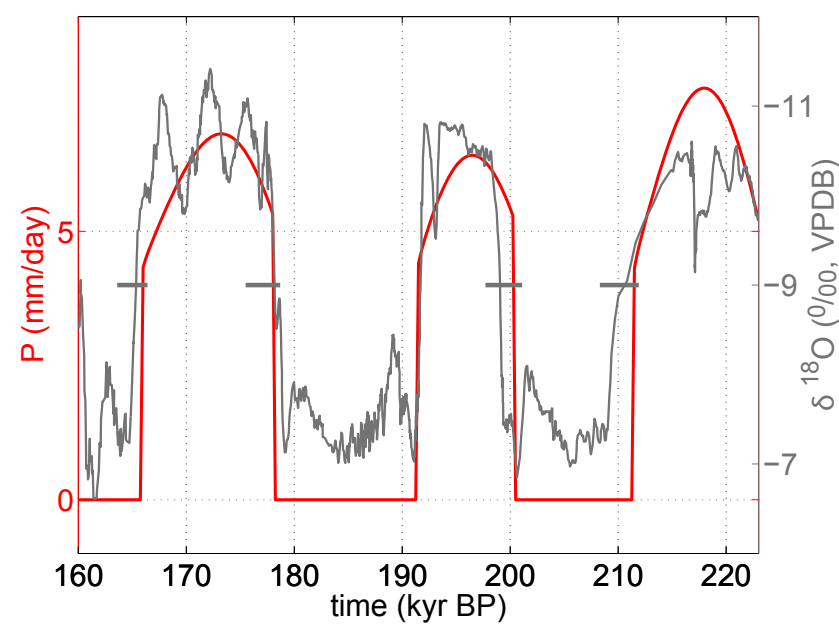

Fig. 10. Grey: Speleothem $\delta^{18} \mathrm{O}$ record from central China, used as EASM proxy for the penultimate glacial period, where more negative values indicate stronger rainfall (Wang et al., 2008). The record is smoothed with a 5-point running average, and dating errors $( \pm 2 \sigma)$ are shown for selected dates (grey horizontal bars). Red: Result of the conceptual model for EASM precipitation $P$ in response to $q_{\mathrm{o}}$ variations driven by northern hemisphere $\left(65^{\circ} \mathrm{N}\right)$ summer insolation, assuming a hysteresis of $0.5 \mathrm{~g} \mathrm{~kg}^{-1}$ width. For illustration, we set $P$ to zero during periods when no monsoon circulation exists according to the model.

clearly seperate from, the present-day range of $q_{\mathrm{o}}$. Only for the Indian region, the distribution of $q_{\mathrm{o}}^{\mathrm{c}}$ overlaps with that of the observed $q_{\mathrm{o}}$; however, when considered pointwise, $q_{\mathrm{o}}^{\mathrm{c}}(t)$ is still lower than $q_{\mathrm{o}}(t)$ for all years.

\section{Application to past abrupt monsoon changes}

Wang et al. (2008) presented a speleothem $\delta^{18} \mathrm{O}$ record from central China that testifies to several large and persistent changes in the strength of the East Asian summer monsoon (EASM) during the penultimate glacial period. These changes are in phase with, but much more abrupt than, precession-dominated oscillations in the Northern Hemisphere summer insolation (NHSI): while the latter follow a quasi-sinusoidal cycle, the form of the monsoon changes rather resembles that of a step-function, with variations around either a strong or a weak mean state, followed by a comparatively rapid transition into the other state (cf. Fig. 2b in Wang et al., 2008). This behaviour is especially apparent before about $160 \mathrm{kyr}$ BP (Fig. 10, grey line) and suggests that non-linear processes inherent to the monsoon system might have amplified changes in external forcing. In particular, the abrupt transitions might have been triggered by the mean insolation, crossing a certain threshold that separated two different states of the monsoon circulation.

Our conceptual monsoon model offers a simplified but robust mechanism to explain such sort of behaviour. It shows 


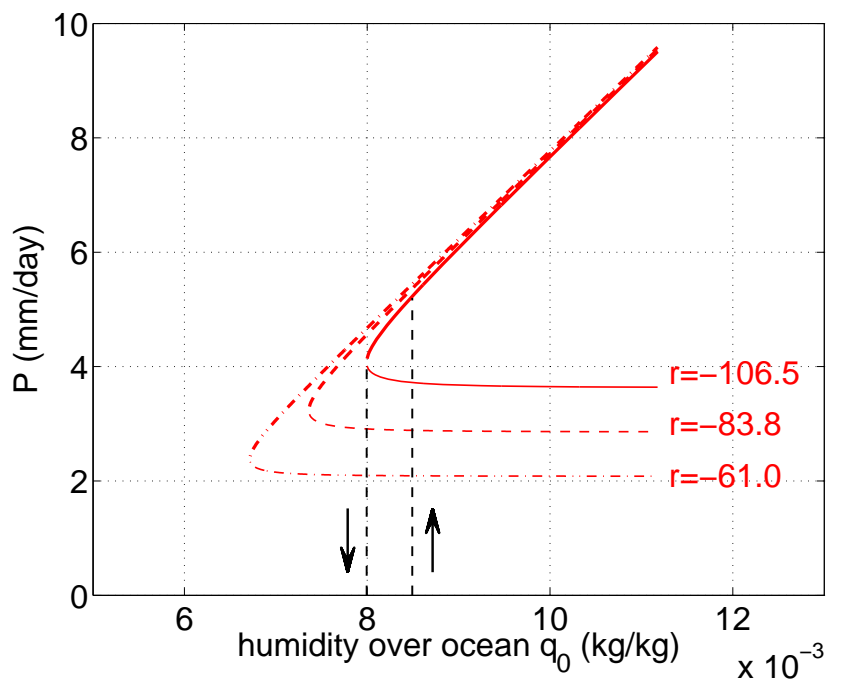

Fig. 11. Physical solution for EASM precipitation $P$ from the conceptual model, for three different values of the non-dimensional parameter $r: \overline{r(t)}$ (dashed), $\overline{r(t)}+\sigma / 2$ (dot-and-dash), and $\overline{r(t)}-\sigma / 2$ (solid), where $r(t)$ is the estimate from NCEP/NCAR reanalysis data, and $\sigma$ denotes a standard deviation. Bold lines indicate the upper, stable branch. The value $\overline{r(t)}-\sigma / 2=-106.5$, which corresponds to a critical threshold $q_{\mathrm{o}}^{\mathrm{c}}=8.0 \mathrm{~g} \mathrm{~kg}^{-1}$, is used for the comparison of the model with EASM proxy data. Vertical dashed lines mark $q_{\mathrm{o}}^{\mathrm{c}}$ and $q_{\mathrm{o}}^{\mathrm{c}}+\Delta_{q}$, where we choose $\Delta_{q}=0.5 \mathrm{~g} \mathrm{~kg}^{-1}$ as the width of an assumed hysteresis that is thought to appear when the threshold is crossed from either side (illustrated by arrows).

that the moisture-advection feedback implies a threshold $q_{\mathrm{o}}^{\mathrm{c}}$ that seperates two regimes: one where a conventional monsoon circulation can exist, and one where it cannot. We therefore speculate that orbital-timescale variations in NHSI and the associated surface temperature changes might have affected evaporation at the ocean's surface, such that average humidity over the ocean persistently crossed the threshold, thus critically altering the moisture supply for the adjacent monsoon region and triggering a transition between the two regimes. Changes in evaporation are governed mainly by changes in surface winds and sea surface temperature (SST). SST could be affected both directly by local/regional insolation changes and by changes in oceanic circulation, coastal upwelling etc. following the large-scale redistribution of heat that goes along with the NHSI variations.

In the following we apply our model to demonstrate how such variations in $q_{\mathrm{o}}$ could have led to monsoon variations consistent with those observed in the proxy record. In doing so, we assume that the values of $\alpha, \beta, \epsilon$, and $q_{\mathrm{L}}^{\mathrm{o}}$ estimated for modern climate from reanalysis data also hold for the penultimate glacial period, and that $R$ was also comparable during that period to its modern value. In reality, $R$ might have also varied in phase with NHSI, however, this variation would have been damped by the stabilizing long-wave radiation feedback. Moreover, a variation of $R$ along with

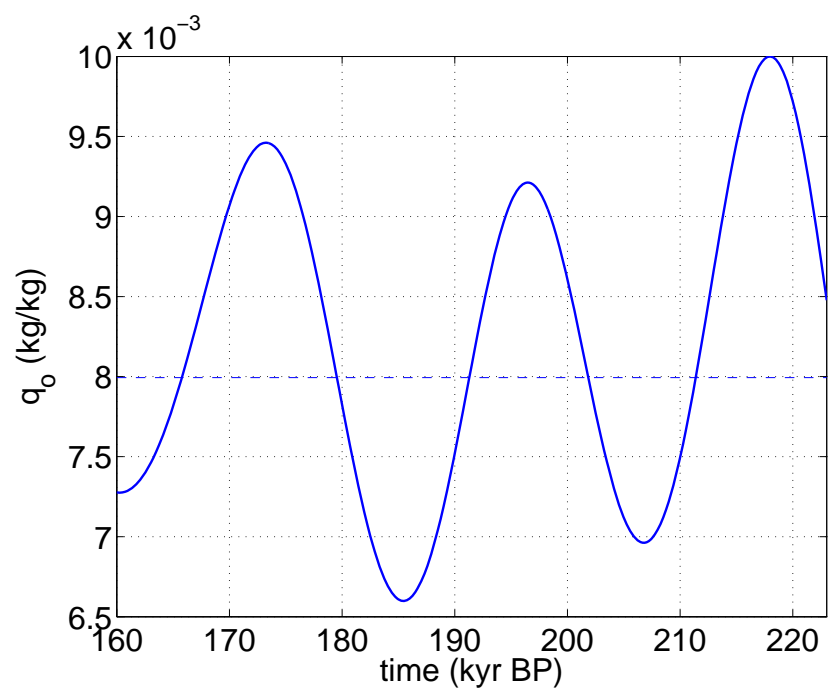

Fig. 12. Time series of $q_{\mathrm{o}}$ used for the application of the conceptual model. $q_{\mathrm{o}}$ is assumed to vary linearly with northern hemisphere $\left(65^{\circ} \mathrm{N}\right)$ summer insolation. The horizontal dashed line marks $q_{\mathrm{o}}^{\mathrm{c}}$.

NHSI would act to exacerbate the threshold effect, moving the threshold towards higher values when insolation, and thus the inferred $q_{\mathrm{o}}$, is low (cf. Fig. 11). Therefore, neglecting variations in $R$ yields a conservative result with respect to the volatility of the system.

The solution of the conceptual model depends on the non-dimensional net radiation $r$. We choose $r=\overline{r(t)}-\sigma / 2=-106.5$, where $\sigma$ denotes a standard deviation (Fig. 11). This corresponds to a critical threshold $q_{\mathrm{o}}^{\mathrm{c}}=8.0 \mathrm{~g} \mathrm{~kg}^{-1}$, which is in the upper part of the estimated $q_{\mathrm{o}}^{\mathrm{c}}$ distribution for the China region (cf. Fig. 9). We further assume $q_{\mathrm{o}}$ to vary linearly with NHSI (Fig. 12; here, we use insolation at $65^{\circ} \mathrm{N}$, but note that insolation changes at lower northern latitudes have a very similar periodicity and relative amplitude on these timescales). The linear relation is chosen such that the maximum $q_{\mathrm{o}}$ is close to the range of presentday observations. Finally, we assume that when the threshold $q_{\mathrm{o}}^{\mathrm{c}}$ is crossed from below (i.e. coming from a non-monsoon regime), it takes an additional increase $\Delta_{q}$ to trigger the transition into the monsoon regime (Fig. 11). The EASM precipitation thus resulting from the conceptual model is shown in Fig. 10 (red line). We set $P$ to zero during periods when the model yielded no physical solution to illustrate the idea that no conventional monsoon circulation can exist during those periods, and no rainfall associated with that circulation would occur. However, we would expect sources of rainfall other than the large-scale monsoon circulation to play a role too, so that actual rainfall would not completely cease during such periods. Note that neither the hysteresis width $\Delta_{q}$, nor the second degree of freedom in the relation $q_{\mathrm{o}} \propto$ NHSI is constrained by data; instead they are chosen such that the result of the conceptual model matches the transition behaviour 
found in the proxy record, taking into account dating errors in the latter (grey bars in Fig. 10).

In this application of the minimal model, we have focused on a section of the paleorecord (ca. 220-160 kyr BP) that spans a series of particularly large and abrupt transitions, and has kept both the model parameters and the parameters of the relation between $q_{\mathrm{o}}$ and NHSI constant. The three NHSI cycles that fall into this period have a similar amplitude, and the rainfall amounts associated with each of the two monsoon regimes are similar across these cycles. This gives us some confidence that the parameters might not have changed too much during this period. While some of the other abrupt transitions in the younger parts of the record are matched reasonably well even with this same set of parameters (not shown), we do not expect the physical processes reflected in these parameters to remain unchanged across two glacial cycles. In order to properly evaluate the conceptual model for the entire period of the record, a more thorough parameter estimation would be needed that takes into account changes in background climate across the last two glacial cycles that could have modified the parameters; moreover, there will still be other physical processes that are important in shaping the record, apart from the simple first-order dynamics represented in our model.

\section{Discussion and conclusions}

We have employed a minimal conceptual model of the monsoon season that embodies the fundamental dynamical processes required to sustain large-scale continental monsoon rainfall. According to this model, a critical threshold $q_{\mathrm{o}}^{\mathrm{c}}$ exists with respect to specific humidity over the ocean region upwind of the continental monsoon region. This threshold follows the central role of the self-amplifying moistureadvection feedback, which governs the atmospheric moist static energy balance during the monsoon season. If $q_{\mathrm{o}}$ falls short of the threshold $q_{\mathrm{o}}^{\mathrm{c}}$, no conventional monsoon circulation can exist over land. The model neglects any processes that are not crucial to the moisture-advection feedback in order to isolate the consequences of this feedback (in particular, the model has no time dependency, and is only valid for the monsoon season). The basic dynamics captured in the model therefore form a necessary condition for sustained continental monsoon rainfall beyond what is accounted for by the zonal-mean dynamics of the intertropical convergence zone. The threshold $q_{\mathrm{o}}^{\mathrm{c}}$ thus defines a domain of existence for a conventional monsoon, and is associated with a non-zero precipitation rate. Outside of this domain of existence, the springtime surface temperature gradient would still trigger the onset of monsoon winds over the continent, but monsoon conditions could not be sustained throughout the summer due to the lack of moist inflow and latent heating. Our results complement those of Levermann et al. (2009), who found a threshold with respect to the net radiation $R$. While $q_{\mathrm{o}}$ can generally be expected to be more volatile than $R$, the model allows for a superposition of changes in both quantities, with the one either damping or amplifying the effect of the other, depending on the direction of change.

As the model contains the physical feedback that causes the threshold behaviour, it can be used to produce meaningful first-order estimates of the threshold values. Within the framework of the minimal model, we have estimated the critical threshold $q_{\mathrm{o}}^{\mathrm{c}}$ for four major monsoon regions using seasonally averaged reanalyses of regional precipitation, net radiation, specific humidity, and temperature for the past sixty years. The resulting distribution of $q_{\mathrm{o}}^{\mathrm{c}}$ can be interpreted either as a noisy estimate of a stationary critical threshold, or as a probability distribution of an interannually varying threshold. The degree to which either of these interpretations is valid depends chiefly on the relative importance of actual variability and observational uncertainty in the parameters $\alpha$ and $\beta$ (see Eqs. 2 and 4), the assessment of which is beyond the scope of this study. However, we have seen that the consideration of an offset in terrestrial specific humidity in Eq. (4) leads to a $q_{\mathrm{o}}^{\mathrm{c}}$ distribution, which is significantly narrower than with the basic version of the model, suggesting that at least some of the spread in $q_{\mathrm{o}}^{\mathrm{c}}$ can be eliminated by making the model more realistic, and thus does not reflect actual year-to-year variability in $q_{\mathrm{o}}^{\mathrm{c}}$.

Consequently, relevant second-order physical processes would have to be included into the model in order to obtain more robust results for $q_{\mathrm{o}}^{\mathrm{c}}$. Probably one of the most important missing processes is evaporation over land (e.g. Eltahir, 1998). Its effect on the heat budget would be mainly to reduce sensible heat flux to the atmosphere, which we have already neglected (Eq. 1,) because it is comparatively small during the rainy season; on the other hand, its effect on the moisture budget (Eq. 3) would be to stabilize the monsoon regime by recycling a part of the atmospheric humidity that is lost to precipitation. Therefore, considering evaporation would tend to move the critical threshold towards lower values of $q_{\mathrm{o}}$.

While the estimation of $q_{\mathrm{o}}^{\mathrm{c}}$ could profit from a refinement of the model, the aim of this study is to demonstrate how the simple concept that the model is based on can help understanding past monsoon variations. The non-linear solution structure of the model implies that transitions into and out of the conventional monsoon regime, caused by small changes in the control variable $q_{\mathrm{o}}$, are associated with abrupt and significant rainfall changes. Changes in $q_{\mathrm{o}}$ could be brought about by various factors acting on different timescales. For instance, as wind speed over the oceans increases due to global warming (Young et al., 2011), evaporation, e.g. in the Arabian Sea, could be affected both directly and via the amount of upwelling of cold waters at the continental margins, and thereby alter the moisture supply for the Indian summer monsoon. For the East Asian summer monsoon (EASM), we have shown that, assuming variations in $q_{\mathrm{o}}$ along orbital-timescale insolation changes, the model yields 
a series of abrupt monsoon transitions similar to that observed in a proxy record of the penultimate glacial period. While the additional assumption of a hysteresis is not crucial for the transition behaviour, it changes the timing of the individual transitions such that they are all consistent, within dating errors, with those found in the proxy record (physically, a hysteresis might be induced by inert climate components such as, e.g. large-scale oceanic circulation or Himalayan glaciation, rather than by atmospheric processes). The idea of a threshold behaviour in monsoon circulations due to the defining mechanism of the moisture-advection feedback may thus be a useful first-order concept for understanding past large-scale monsoon changes. The conceptual model investigated here may also serve as a basic building block that can be made more realistic by the inclusion of other relevant processes and by a more detailed estimation of the model parameters. For a complete understanding of monsoon variations on multiple timescales, of course, more complex models will have to be invoked.

\section{Appendix A}

\section{Methods}

NCEP/NCAR reanalysis data was obtained as monthly-mean time series (January 1948-December 2007), and regionally aggregated as indicated in Table $1 . U$ is averaged vertically between $850 \mathrm{hPa}$ and $1000 \mathrm{hPa}(925 \mathrm{hPa}$ and $1000 \mathrm{hPa}$ for the shallower circulation in Africa), $q_{\mathrm{o}}$ between $600 \mathrm{hPa}$ and $1000 \mathrm{hPa}\left(925 \mathrm{hPa}\right.$ and $1000 \mathrm{hPa}$ for Africa), $q_{\mathrm{L}}$ between $400 \mathrm{hPa}$ and $1000 \mathrm{hPa}$, and $\Delta T$ over the entire atmospheric column, as represented in the reanalysis data.

Acknowledgements. This work was funded by the Heinrich Böll Foundation, the German National Academic Foundation, and the BMBF PROGRESS project (support code 03IS2191B). NCEP reanalysis derived data was provided by the NOAA/OAR/ESRL PSD, Boulder, Colorado, USA, from their website at http://www.esrl.noaa.gov/psd/.

Edited by: D. Fleitmann

\section{References}

Auffhammer, M., Ramanathan, V., and Vincent, J. R.: Integrated model shows that atmospheric brown clouds and greenhouse gases have reduced rice harvests in India, P. Natl. Acad. Sci., 103, 19668-19672, 2006.

Brovkin, V., Claussen, M., Petoukhov, V., and Ganopolski, A.: On the stability of the atmosphere- vegetation system in the Sahara/Sahel region, J. Geophys. Res., 103, 31613-31624, 1998.

Burns, S. J., Fleitmann, D., Matter, A., Kramers, J., and Al-Subbary, A. A.: Indian Ocean Climate and an Absolute Chronology over Dansgaard/Oeschger Events 9 to 13, Science, 301, 1365-1367, 2003.
Clark, C. O., Cole, J. E., and Webster, P. J.: Indian Ocean SST and Indian summer rainfall: Predictive relationships and their decadal variability, J. Climate, 13, 2503-2519, 2000.

Claussen, M.: Modeling bio-geophysical feedback in the African and Indian monsoon region, Clim. Dynam., 54, 247-257, 1997.

Dash, S. K., Singh, G. P., Shekhar, M. S., and Vernekar, A. D.: Response of the Indian summer monsoon circulation and rainfall to seasonal snow depth anomaly over Eurasia, Clim. Dynam., 24, 1-10, 2005.

Eltahir, E. A. B.: A soil moisture-rainfall feedback mechanism: 1. Theory and observations, Water Resour. Res., 34, 765-776, 1998.

Goswami, B. N. and Xavier, P. K.: ENSO control on the south Asian monsoon through the length of the rainy season, Geophys. Res. Lett., 32, L18717, doi:10.1029/2005GL023216, 2005.

Goswami, B. N., Madhusoodanan, M. S., Neema, C. P., and Sengupta, D.: A physical mechanism for North Atlantic SST influence on the Indian summer monsoon, Geophys. Res. Lett., 33 , L02706, doi:10.1029/2005GL024803, 2006.

Gupta, A. K., Anderson, D. M., and Overpeck, J. T.: Abrupt changes in the Asian southwest monsoon during the Holocene and their links to the North Atlantic Ocean, Nature, 421, 354357, 2003.

Hahn, D. G. and Shukla, J.: An apparent relationship between Eurasian snow cover and Indian monsoon rainfall, J. Atmos. Sci., 33, 2461-2462, 1976.

Hong, Y., Hong, B., Lin, Q., Zhu, Y., Shibata, Y., Hirota, M., Uchida, M., Leng, X., Jiang, H., Xu, H., Wang, H., and Yi, L.: Correlation between Indian Ocean summer monsoon and North Atlantic climate during the Holocene, Earth Planet. Sc. Lett., 211, 371-380, doi:10.1016/S0012-821X(03)00207-3, 2003.

Kistler, R., Kalnay, E., Saha, S., White, G., Woollen, J., Chelliah, M., Ebisuzaki, W., Kanamitsu, M., Kousky, V., den Dool, H. V., Jenne, R., and Fiorino, M.: The NCEP/NCAR 50-year reanalysis, B. Am. Meteorol. Soc., 82, 247-267, 2001.

Knopf, B., Flechsig, M., and Zickfeld, K.: Multi-parameter uncertainty analysis of a bifurcation point, Nonlin. Processes Geophys., 13, 531-540, doi:10.5194/npg-13-531-2006, 2006

Krishnamurthy, V. and Goswami, B. N.: Indian monsoon-ENSO relationship on inter-decadal timescale, J. Climate, 13, 579-595, 2000.

Kucharski, F., Molteni, F., and Yoo, J. H.: SST forcing of decadal Indian monsoon rainfall variability, Geophys. Res. Lett., 33, L03709, doi:10.1029/2005GL025371, 2006.

Kumar, K. K., Kumar, K. R., Ashrit, R. G., Deshpande, N. R., and Hansen, J. W.: Climate impacts on Indian agriculture, Int. J. Climatol., 24, 1375-1393, doi:10.1002/joc.1081, 2004.

Levermann, A., Schewe, J., Petoukhov, V., and Held, H.: Basic mechanism for abrupt monsoon transitions, P. Natl. Acad. Sci., 106, 20572-20577, 2009.

Liu, X. and Yin, Z:: Sensitivity of East Asian monsoon climate to the uplift of the Tibetan Plateau, Palaeogeogr. Palaeocl., 183, 223-245, 2002.

Meehl, G. A.: Influence of the Land Surface in the Asian Summer Monsoon: External Conditions versus Internal Feedbacks, J. Climate, 7, 1033-1049, 1994.

Parthasarathy, B., Munot, A., and Kothawale, D.: Regression model for estimation of Indian foodgrain production from summer monsoon rainfall, Agr. Forest Meteorol., 42, 167-182, 
doi:10.1016/0168-1923(88)90075-5, 1988

Petoukhov, V. K.: Two mechanisms of temperature oscillations in a thermodynamical model of the troposphere-stratosphere system, Izvestiya, Atmos. Ocean. Phys., 18, 126-137, 1982.

Petoukhov, V., Ganopolski, A., Brovkin, V., Claussen, M., Eliseev, A., Kubatzki, C., and Rahmstorf, S.: CLIMBER-2: a climate system model of intermediate complexity, Part I: model description and performance for present climate, Clim. Dynam., 16, 117, 2000.

Ramanathan, V., Chung, C., Kim, D., Bettge, T., Kiehl, J. T., Washington, W. M., Fu, Q., Sikka, D. R., and Wild, M.: Atmospheric brown clouds: Impacts on South Asian climate and hydrological cycle, P. Natl. Acad. Sci., 102, 5326-5333, 2005.

Rashid, H., England, E., Thompson, L., and Polyak, L.: Late Glacial to Holocene Indian Summer Monsoon Variability Based upon Sediment Records Taken from the Bay of Bengal, Terr. Atmos. Ocean. Sci., 22, 215-228, doi:10.3319/TAO.2010.09.17.02(TibXS), 2011.

Robock, A., Mu, M., Vinnikov, K., and Robinson, D.: Land surface conditions over Eurasia and Indian summer monsoon rainfall, J. Geophys. Res., 108, 4131, doi:10.1029/2002JD002286, 2003.

Srinivasan, J.: A simple thermodynamic model for seasonal variation of monsoon rainfall, Current Sci., 80, 73-77, 2001.

Wang, B.: The Asian monsoon, Springer-Verlag, Berlin, Heidelberg, New York, 2005.

Wang, P., Clemens, S., Beaufort, L., Braconnot, P., Ganssen, G., Jian, Z., Kershaw, P., and Sarnthein, M.: Evolution and variability of the Asian monsoon system: state of the art and outstanding issues, Quaternary Sci. Rev., 24, 595-629, 2005.

Wang, Y., Cheng, H., Edwards, R. L., He, Y., Kong, X., An, Z., Wu, J., Kelly, M. J., Dykoski, C. A., and Li, X.: The Holocene Asian Monsoon: Links to Solar Changes and North Atlantic Climate, Science, 308, 854-857, 2005.
Wang, Y., Cheng, H., Edwards, R. L., Kong, X., Shao, X., Chen, S., Wu, J., Jiang, X., Wang, X., and An, Z.: Millennial- and orbital-scale changes in the East Asian monsoon over the past 224,000 years, Nature, 451, 1090-1093, 2008.

Webster, P. J.: The Elementary Monsoon, in: Monsoons, edited by: Fein, J. S. and Stephens, P. L., John Wiley, New York, N.Y., 332, 1987a.

Webster, P. J.: The Variable and Interactive Monsoon, in: Monsoons, edited by: Fein, J. S. and Stephens, P. L., John Wiley, New York, N.Y., 269-330, 1987b.

Webster, P. J., Magaña, V. O., Palmer, T. N., Shukla, J., Tomas, R. A., Yanai, M., and Yasunari, T.: Monsoons: Processes, predictability, and the prospects for prediction, J. Geophys. Res. 103, 14451-14510, 1998.

Yang, J., Liu, Q., Xie, S.-P., Liu, Z., and Wu, L.: Impact of the Indian Ocean SST basin mode on the Asian summer monsoon, Geophys. Res. Lett., 34, L02708, doi:10.1029/2006GL028571, 2007.

Young, I. R., Zieger, S., and Babanin, A. V.: Global Trends in Wind Speed and Wave Height, Science, 332, 451-455, doi:10.1126/science.1197219, 2011.

Zhang, P., Cheng, H., Edwards, R. L., Chen, F., Wang, Y., Yang, X., Liu, J., Tan, M., Wang, X., Liu, J., An, C., Dai, Z., Zhou, J., Zhang, D., Jia, J., and Johnson, K. R.: A Test of Climate, Sun, and Culture Relationships from an 1810-Year Chinese Cave Record, Science, 322, 940-942, 2008.

Zickfeld, K., Knopf, B., Petoukhov, V., and Schellnhuber, H. J.: Is the Indian summer monsoon stable against global change?, Geophys. Res. Lett., 32, L15707, doi:10.1029/2005GL022771, 2005. 